University of Wollongong

Research Online

Faculty of Informatics - Papers (Archive)

Faculty of Engineering and Information

Sciences

October 2001

\title{
Assessing hybrid classes in a flexible learning environment
}

M. Lawrence-Slater

University of Wollongong

Follow this and additional works at: https://ro.uow.edu.au/infopapers

Part of the Physical Sciences and Mathematics Commons

\section{Recommended Citation}

Lawrence-Slater, M.: Assessing hybrid classes in a flexible learning environment 2001.

https://ro.uow.edu.au/infopapers/79

Research Online is the open access institutional repository for the University of Wollongong. For further information contact the UOW Library: research-pubs@uow.edu.au 


\title{
Assessing hybrid classes in a flexible learning environment
}

\begin{abstract}
This paper describes the development of a regime comprising a teaching platform and associated assessment processes. The objective behind these is to enable the equitable assessment of student assignments in hybrid courses. In this paper, the term hybrid refers to courses where the student body comprises both campus-based and off-campus students. Additionally, in either of these groups students may elect to undertake their studies using online resources rather than attend in person. The paper commences with a background discussion on the problem and reasons for seeking alternative approaches to teaching and assessment in hybrid courses. This is followed by a detailed examination of the teaching processes, assessable components and the tools which are pivotal to the process. The paper describes the rationale and objectives behind each, the relationship between the different components and describes the relationship of each to the process as a whole. The paper concludes with some of the issues encountered during the evolution of the regime and discussion on further direction in respect to future research and development.
\end{abstract}

\section{Keywords}

distance learning, teaching

Disciplines

Physical Sciences and Mathematics

\section{Publication Details}

This paper originally appeared as: Lawrence-Slater, $\mathrm{M}$, Assessing hybrid classes in a flexible learning environment, 31st Annual Frontiers in Education Conference, 10-13 October 2001, 2, F3C - 1-6. Copyright IEEE 2001. 
Session F3C

\title{
ASSESSING HYBRID CLASSES IN A FLEXIBLE LEARNING ENVIRONMENT
}

\author{
Michael Lawrence-Slater ${ }^{I}$
}

\begin{abstract}
This paper describes the development of a regime comprising a teaching platform and associated assessment processes. The objective behind these is to enable the equitable assessment of student assignments in hybrid courses. In this paper, the term hybrid refers to courses where the student body comprises both campus-based and off-campus students. Additionally, in either of these groups students may elect to undertake their studies using online resources rather than attend in person. The paper commences with a background discussion on the problem and reasons for seeking alternative approaches to teaching and assessment in hybrid courses. This is followed by a detailed examination of the teaching processes, assessable components and the tools which are pivotal to the process. The paper describes the rationale and objectives behind each, the relationship between the different components and describes the relationship of each to the process as a whole. The paper concludes with some of the issues encountered during the evolution of the regime and discussion on further direction in respect to future research and development.
\end{abstract}

Index Terms - active participation, collaborative groups, flexible learning, hybrid classes, peer assessment

\section{INTRODUCTION}

In the information-based New Economy, the benefits and possibilities offered by Information and Communications Technology (ICT), to organisations of all types and sizes, has led to an exponential growth in the use of ICTs. This growth has resulted in a demand, and subsequent shortage, of persons with relevant ICT skills. Often, this shortfall in the ICT workforce is being met by students, both graduate and undergraduate, who take up regular employment during the course of their formal degree studies.

The consequent need by students to combine their studies and paid employment has led to many enrolling into distance-learning (DL) versions of their courses. But, DL versions of courses are not always offered by institutions. In this event, when students attempt to balance their studies and employment, there is the possibility of their absence from some, if not all, of the formal classes in their courses.

As that situation started to develop, the author began to consider what possibilities there may be for course members to gain benefit from this practice, rather than be disadvantaged. The outcome of these deliberations was the identification of a need for a flexible framework wherein courses might be comprised of students who attend the formal classes and others who may, or may not, attend a few, or perhaps none, of the classes.

Once the possibility of such hybrid classes had been identified, it became apparent that, in some cases, the current forms of assessment were not always suitable. The first need, then, was to create a flexible, equitable assessment regime which could be used in hybrid classes.

It is important at this stage to note, that while this paper describes the creation of this assessment regime as though it were a single event, it is an ongoing process and the current status reflects an evolution over several semesters. Over this time input from students and the experience gained in its use has enabled a number of incremental changes to improve, simplify and make more robust the process when used by academic or student alike. As well, new facilities added refinement to the process.

\section{Objectives}

As is probably the case in many institutions, the Codes of Practice at the University of Wollongong [1] which relate to teaching and assessment require that the total marks awarded to a student for a single course be based upon (a) not less than three assessment tasks, (b) that no single task represent more than a certain percentage of the subject total mark and, (c) that a proportion of the mark for a student be based upon individual, rather than group tasks.

Feedback through progressive assessments throughout a course, rather than at the end, provides students with the opportunity of improvement in the quality of their work. Kolb illustrates this in his Learning Cycle [2] in which, through a continuing cycle of four processes - Experiencing, Reflection, Conceptualisation and Planning - learners gain an understanding through an experience, learn from it and modify their behavior to achieve an incremental improvement in their future work. In essence, Kolb's Learning Cycle is an alternate version of the Deming/Shewhart Wheel used in the management of Quality. Kolb's Experiencing/Reflection/Conceptualisation/Planning equate directly with the Deming/Shewhart Do/Check/ Act/Plan. There is little difference in the processes of incremental improvement in education or a manufacturing organisation.

From the teaching and learning perspective, progressive feedback is beneficial to academic and student alike and is an opportunity for improvement. This feedback is often more effective through the formal assessment of student assignments of a defined scope rather than through the

\footnotetext{
'Michael Lawrence-Slater, University of Wollongong, School of Information Technology \& Computer Science, Northfields Avenue, Wollongong, NSW 2500, Australia,mls@uow.edu.au

0-7803-6669-7/01/\$10.00 $@ 2001$ IEEE

$31^{\text {st }}$ ASEE/IEEE Frontiers in Education Conference

October 10 - 13, 2001 Reno, NV

F3C-1
} 


\section{Session F3C}

evaluation of the work-in-progress on a larger task of longer duration.

The structuring a large task into a number of manageable sub-tasks enables the course designer to set a number of such 'progressive assessment' milestones over the duration of a course and, in this way, provide students with feedback on their work-to-date, irrespective of the size of the ultimate project task. Such a practice of progressive assessment also enables the assessment of individual students, even when the major course project is being undertaken within a group of collaborating students.

Having determined an operational framework, the next phase was to identify and understand the key elements of the proposal which were to -

- determine the type and form of tasks which would be usable in this form of assessment

- understand how the nominated tasks could be used and, importantly, how they may integrate

- determine the tools and techniques necessary to enable consistent, equitable results whether used by academic staff, or members of the student body

- A further, longer term objective was to determine whether such a regime would (a) be scalable, to cater for the steady increase in class sizes, and (b) would reduce the administrative workload of academic staff.

The outcome of this deliberation was the identification of the integrated suite of teaching processes, techniques and tools described in the following sections.

\section{TEACHING PROCESSES}

Three teaching processes form the backbone of the assessment regime. These are online learning, collaborative group projects and peer assessment.

\section{Online learning}

It may seem paradoxical that online learning be included, albeit briefly, in a paper discussing courses where that mode of delivery is an integral part of the process. Online courses, in particular those hosted on the Internet, are becoming an increasingly common method of delivering learning materials. Despite some reservations $[3,4]$ online delivery and learning is becoming a widely used technique in a wide variety of professions and disciplines.

Whether campus-based, or off-campus, students in the author's courses are expected to make extensive use of online facilities. For example, all information and communication is made available to students through the course web site. During the term, all course-related material is loaded onto the course web site. This material includes lecture notes, course information, student contributions and, through the What's New pages, any changes, etc. In addition, one element of the student's participation mark is derived through the assessment of the work of their peers and other groups. This is done through this work being loaded to the course web site where it is available to all.

\section{Collaborative, group projects}

Collaborative, or group projects, are emerging as a widely used technique in student-centred learning. It is argued by McAlpine [5] that one key element of collaborative projects is the constructivist nature of group collaboration where the subject matter, context and experience of the learners creates a framework for effective learning. In addition, collaborative group work can provide an opportunity for students to learn, by taking part in the type of real-world collaborative experiences which are becoming a necessity in today's global, information-based economy [6].

Collaborative group work can present a challenge to students, particularly those learners who adopt a passive approach in their learning [7]. Dringus notes that in an online environment, such learners will need to make a dramatic shift in their learning perspective to enable their acquisition of information through active search rather than passive receipt of material presented by teachers [8].

The first requirement in group-based work is the formation of the student groups undertaking the work Groups can be formed through a self-selection process, they may be formed autocratically by the teacher, or may even form though a random selection of members. While it may be pleasant for students to form their own groups, and in some circumstances even produce a predictably better outcome, the self-selection method, particularly in respect of the interaction required to form a group online, may be too timeconsuming and complex [7]. Early in the evolution of this assessment regime, student self-selection was trialled in one of the courses. In that case, groups were to be formed through the students promoting their interests on the course web site and inviting others to join them. Even with a relatively small class of around seventy students, this method was not a great success as it took an excessive amount of the time student groups had available to them for the completion of their major assessment tasks. It is generally easier, then, for the teacher to moderate the formation of the groups.

There is no 'reasonable' size for a student group project. Size is usually determined by factors such as project duration, requirements and even, academic discipline. For example, a computer science project may require the completion of a program, user guide and other documentation whereas an English language project requires a different form of tangible deliverable. In the case of the author's courses, the group project usually involves a related series of deliverables. The goal of these projects is usually the production of a journal, or collaborative report, based on an important aspect of ICT. Examples of these might be ICT in Education, The Social Impact of ICTs or The Impact of ICT in the Workplace. Whilst working on the final outcome, all groups are required to produce interim deliverables related to their topic. The interim items comprise a seminar paper and a 
formal seminar presentation. All three of these assessment components address the group topic, but in a different form.

There is no optimum number of members in a group. management style of the group, as much as anything else, is a determining factor in this respect. In the author's courses, the number of group members varies between three and seven members.

It is not unknown for students to request that they be permitted to undertake a group project alone. It is the policy of the University of Wollongong, as it may be in other institutions, that such requests be accommodated and students be permitted to do so. To cater for these cases, and in the cause of equity, it is the author's practice to structure the assignments in such a way as to enable these students to complete a close approximation of the work undertaken by the groups.

Once formed, groups then meet as necessary, either in person or through the electronic media, or both. When requested, the group tutor and the course coordinator are also available for consultation. While consultation is usually in person, at pre-arranged times, it may also take place, by arrangement, using the preferred medium of the group; for example audio, video or web-conferencing.

\section{Peer and self-assessment}

The process known as peer assessment is commonly used in defining two quite different activities. One usage of the term reflects a process whereby the work of an individual, or group, is assessed by their peers. This form of the term describes, for example, the process commonly used in the peer review of papers for a journal or conference. In the second form, the term describes a process where each member of a group gives their personal assessment of the overall contribution to a project made by themselves and the other members of their group. For the purpose of this paper, the first form will be termed 'peer assessment' and is used to describe the assessment of the work of groups, or individuals other than one's own. The second form will be termed 'selfassessment'. Differences between these assessment forms are not only that of scope, but also whether the assessor and assessed are known to each other.

Peer assessment has some significant learning benefits. For example, students assessing the work of others on a particular topic not only gather other valuable perspectives on the topic, but also, enhance their skills of critical analysis [9]. The technique, then, reinforces students learning, adds to their understanding of the topic and hones their critical facilities. The author has also gathered some incomplete evidence, supported by Clifford [10] which suggests that students take much greater care in the preparation of their work where it is to be assessed by their peers.

As stated earlier, self-assessment is used to describe a process of self analysis of the members within a group. $\mathrm{Li}$ [11] points to some shortcomings in this process, since marks may be affected due to the subjectivity of members within a group. Li suggests a method where such subjective influences may be eliminated through a process of weighting and the normalisation of the 'raw' assessment tally. Unlike peer assessment, where the assessor may not have any contact with the assessed, it may be possible that the marks derived through self-assessment are influenced by inter-personal relationships within a group. Certainly, there is anecdotal evidence of grievances within groups where some members feel their contribution to group tasks has been greater than that of the other members.

In respect of the mark derived through peer assessment, Cheng and Warren [12] present evidence which shows that there is little variation in the marks derived from student and teacher assessments of the same material. There was, however, an opposite outcome in another study conducted by Bridges et al. [13]. In their research, an analysis of the marks gained by students in the same ten subjects within seven English universities revealed the possibility of wide variation (Standard Deviation 7.4-17.0) in the marks awarded. Bridges et al. attributed much of this variation to the requirement for assessors to provide a percentage mark and deduced that part of this variation was due to the characteristics of different disciplines.

Over the time in which the assessment regime being discussed in this paper has been used, there have only been comparatively small differences (around $5 \%$ ) in the marks received from teacher and student assessors. The author believes that this stability results from the use of an assessment form together with a set of detailed user instructions. When completed, the assessors forward their completed assessment forms to an assessment coordinator and the final percentage mark is awarded based on an analysis of the assessment forms. The ultimate mark awarded for any particular piece of work is based upon a combination of teacher and student assessment. However, in the interest of progressive feedback and, therefore, improvement groups are advised of the mark awarded by the teacher as soon as it is available since the student assessment contributions may continue over a further period of weeks.

\section{ASSESSABLE COURSE COMPONENTS}

A typical course comprises a number of integrated, but separately assessable components which include -

- Class participation

- Student contribution

- Seminar paper

- Seminar presentation

- Journal or report

- Examination - sometimes electronic

These components are described in the following sections with discussion including a description of the way in which they are used together with the techniques, methods and tools employed and, where appropriate, how the integrate. 


\section{Class participation}

Today, it is accepted wisdom that the active participation of students in class is more beneficial to leaming [7] than the simple attendance of students at lectures and tutorials. In fact, from the earliest times, the intent behind tutorials was that they act as a forum where a topic could be openly discussed enabling its greater understanding by all participants.

Participation marks are structured to recognise the contribution of individual students to the class, no matter what form, whether face-to-face, electronic, written or verbal which their contribution may take. The following five items have been used to-date in assessing student participation.

(i) Class management: Excepting the first week of the term, each week, for the duration of the course, every tutorial class is 'managed' by one of the groups in that class. Class management responsibilities focus on the group leading class discussion on the course topic of the week.

(ii) Assessment of seminar presentations: Using a form designed for the purpose each student assesses that week's seminar presentation. The form lists five criteria on which the presentation is to be judged. These five are the relevance of the presentation to the topic of the week, the depth and knowledge shown by the presenters, how interesting and original, the group response to questions and the use of available time. To ensure that assessment is consistent across all classes, instructions are provided on the use of the assessment form.

(iii) Active participation: The contribution made by each student as observed and recorded by the class tutor. Students are expected to actively participate during classes and to interact in seminar presentations

(iv) Assessment of seminar papers: Every student has the opportunity to read any of the seminar papers which appear on the subject web-page. Again, an assessment form is used with descriptive guideline notes being provided to aid in that task.

(v) Contribution of interesting material: Students are encouraged to contribute any interesting and relevant material found during their research into their topic. These are then loaded onto the course web site to be a resource for all course members. The inclusion of these materials is not automatic, however, and requires a donor commentary on its relevance to the course. It is not sufficient to merely send the URL or a reference to the material. The submitted material is placed on the subject web

It may be reasonable to presume that components (i), (ii) and (iii) require the physical attendance of students at the class, and that the other components are a web-based activity. This is not necessarily the case, as it is possible, and allowable for all participation components to be submitted and conducted and electronically, or in person.

\section{0-7803-6669-7/01/\$10.00 C 2001 IEEE}

During the term, all student activity is noted and tallied into the software model used in calculating the final student marks. To date, using this scheme, it has not been possible to provide students with their participation mark until the course is completed. However, changes are underway in the software model to enable students a view of their progressive mark to date, including participation.

To encourage student participation the mark awarded is a generous proportion of the course total; typically in the range ten to twenty percent of the course total.

No particular proportion of the participation mark is awarded to these participation components. Thus, while it has not occurred to date, it is possible for a student's participation mark to be derived from just one of the components.

\section{Seminar presentation and paper}

In the week following the management of the tutorial class each group submits a paper and makes a formal presentation on the outcome of their research. The sources used include the course notes, the independent researches of the group and any other information derived during their management of the class.

Each week, the papers for all groups presenting in that week are made available on the course web site for perusal and assessment by all course members.

\section{Group journal or report}

The major project and deliverable of the course is the production by each group of a journal on a particular theme, or a collaborative report on an aspect of ICT.

A group journal requires a title appropriate to the journal theme and comprises a cover, an editorial commentary and a minimum of four papers, or one paper from each member of the group. A group report follows the conventions of an industry or government report, and is usually an in-depth examination into one particular topical area. The report requires a title page, management overview, table of contents and a structure of sections or chapters relevant to the topic being examined.

As a group project, journals and reports each have their own benefits. The journal in this context, however, has distinct advantages over a report. In a journal, the work of all members of the group is readily identifiable with each having a similar degree of difficulty. A journal is also scalable and can cater for any number of group members. Finally, with a journal, the projects of all groups are capable of direct comparison.

\section{Examinations}

Electronic examinations and electronic assessment are becoming fairly common. In particular, electronic tests are being set in the 'hard' sciences where a qualitative answer is required and where there is no possibility of ambiguity in the question or answer. These test papers usually contain

October 10 - 13, 2001 Reno, NV 


\section{Session F3C}

multiple-choice, yes/no, true/false answers or defined formulae Such electronic tests, however, require a controlled examination environment, at least where the use of external, non-allowable materials is concerned.

It is not always possible to set such absolute tests in softscience and humanities courses where an examination answer usually require a reasoned, qualitative answer presented in the form of an argument, rather than a true/false, yes/no response. While an electronic examination in a controlled test environment is feasible, it is not a practical possibility in hybrid classes where students may, or may not be able to attend. In a hybrid class, it is difficult to formulate examination questions which could cater for the differen members of the class and still be equitable.

Electronic, online examinations have been set by the author. These have taken the form of a 'take-home' examination questions requiring a reasoned, properly referenced discussion as an answer. In these, the same questions were released to all students on the course web site at a pre-arranged time. The student's answers were required to be returned electronically by a certain time. Although this worked relatively well, there were a number of networkrelated issues and difficulties.

\section{ASSESSMENT TOOLS}

The tools used in this regime include a set of assessment forms and guidelines on how to complete them. The tools also contain a comprehensive computer model which is used in conjunction with the assessment forms to determine the mark for an assessment task. Used together, by all course assessors both academic and student, these tools enable a great degree of objectivity and equity when determining a mark. This is particularly important when different people are assessing the same work.

Assessment forms: To cater for differing criteria, an assessment form is provided for each of the assessable tasks seminar presentation, seminar paper and journal/report. Different forms are also provided for each class of assessor, i.e. academic and student, the student pro-forma usually being a subset of the academic form. In the interests of familiarity and usability, every form, follows the same design principles in respect of structure and format. All assessment forms contains eight columns: the first describes the items to be assessed, the next six columns are a six-point Lickert scale which range in value from Poor to Excellent. The last column allows comments to be made by the assessor. In addition, most of the forms contain a free-form comments field.

Assessment form guidelines: The course web site contains guidelines for the completion of every assessment form. For each of the items on the form there are instructions on its completion and value. These include the criterion to be followed in assessing that item and, in certain cases, direct the specific value to be assigned. For example, if the guidelines require an author name, and it is missing, then the assessor would be directed to mark that item as Poor.
Quite apart from their primary role as guidelines to completing the assessment forms, they also provide transparency in the criteria used in determining the marks for an assessment task. Students have also found these guidelines useful as an aide-memoire, since they specify the items which should be present in any piece of work and may be used as guidelines in the completion of their own work.

Computer model: The tools contain the computer model used to tally the marks from the various assessment forms and compute the marks for each of the assessment tasks. If necessary, the model can be used to normalise the marks between groups and to scale the final student marks. Although not meaningful in the early weeks of a term, due to a lack of data, the model can also provide students with a progressive course marks.

\section{ISSUES}

Throughout the evolution of this assessment regime, a number of issues have arisen, some minor, others less so. The issues range from those to be found in conventional classes including plagiarism and late submission to others which are more specific to online classes. The latter includes network congestion, time-zones, compatible software, the submission of work containing viruses and sufficient filestore to cater for the receipt of large volumes of work, such as examination papers. Finally, there are a other serious issues which require great consideration. These include cultural difference, the motivation of students and the potential for social isolation through the use of ICTs.

Plagiarism: Most institutions have a policy in relation to plagiarism. As Austin [14] shows it is now easier for a student to obtain material over the Internet than it was in the past. Often, though, it may be easier to find incorrectly attributed sourced material through the use of the Internet than it was to find it in the past.

Penalties for late submission: It would be unusual to find a course which did not have some provision to penalise students for the late submission of assignments. However, in an online environment is it reasonable to penalise a student for network congestion, or is that part of the lesson learned? Cultural difference:S ome researchers $[15,16]$ point out the differences in understanding which occur with students from different cultural backgrounds. A case study conducted by McLoughlin and Oliver [17] into tertiary education for indigenous online learning deduced that it is important to take cultural difference into account when designing a course, since '...it enables learners to develop a cognitive anchor for new concepts...'. However, this study concluded that a lack of 'localised' design is not a major inhibitor to learning.

Social isolation: In 1996, a research team from Carnegie Mellon University [18] conducted a study into the benefits to be derived through the use of the Internet. The unexpected outcome of this research [19] was that participants in the study began to show increasing indications of social isolation 
and depression as the study progressed. Crook [20], on the other hand observes that in '...significant respects, the computer has facilitated socially organised learning...'. An issue does arise, however, relating to a teacher's duty-of-care. While it is possible to identify and even help with the problems of a flesh-and-blood student, can the same level of care be extended to a remote student?

\section{RESULTS}

Although it has evolved over a substantial period, in many respects, this research program is still at an early stage. To date, performance data has been gathered for the pragmatic purpose of incremental improvement of the process rather than for publication. An increasing body of data is being gathered with each iteration of this process and will be analysed following the research outlined below.

\section{Further research}

The process is proving effective and further research activity has been scheduled in the coming year to include -

- a comparative study to evaluate whether the same effects of the process are found in another institution

- a comparative analysis of student performance within each component and overall. To study, for example, whether physical class attendance has any affect on student examination performance.

- a pilot study to examine extending the process to include completely student managed tutorial classes.

\section{Future developments}

Developments identified at this stage are both technological and organisational.

Technological advances, particularly in the area of compression techniques make the provision of streaming audio and video clips possible as supplements to the course notes. As well, these advances make web-conferencing a realistic possibility.

Organisationally, the this assessment regime has identified a number of areas where administrative tasks might be transferred from academic to administrative staff.

\section{CONCLUSION}

The intention of this paper has been to relate the development and application of assessment methods which may be applied to courses which include campus-based and non-campus students in a face-to-face and an online environment.

As is evidenced in many disciplines, practitioners gain real benefit from applying the theoretical background gathered through their studies within the perspective of a practical framework in their workplace. For the students in these courses, the understanding and knowledge gained as a by-product of the process adds value to their study experience. Through the collaborative and group work, in an online environment, students students gain knowledge and insights into the ways in which technology may be most fruitfully used in the workplace. Finally, they engage in a process of learning-by-doing which mimics many of the techniques they will be using in their future profession.

\section{REFERENCES}

[1]. The University of Wollongong, Codes of Practice - Teaching and Assessment, web site http://www.uow.edu.au/about/teaching/teaching_code.html

[2]. Kolb, D.A., Experiential learning: Experience as the source of learning and development, 1984, Englewood Cliffs, NJ: Prentice Hall.

[3]. Wired News, Distance Learning No Bargain?, 1999, web site http:wired.com/news/print/0,1294,21595,00.html

[4]. Hara, N. and Kling, R., Students' Frustrations with a Web-based Distance Education Course: A Taboo Topic in the Discourse, 1999, web site http://www.shs.indiana.edu/CSI/wp99 01.html

[5]. McAlpine, I., "Collaborative learning online", Distance Education, 2000, Vol. 21, No. 1, pp. 66-80

[6]. Butera, F., "Adapting the Pattern of University Organisation to the Needs of the Knowledge Economy", European Journal of Education: research, development and policies, 2000, Vol. 35, No. 4, December 2000 , pp. $403-420$

[7]. Harasim, L., et al., Learning Networks: A Field Guide to Teaching and Learning Online, 1995, Cambridge: The MIT Press.

[8]. Dringus, L.P., "Towards Active Online Learning: A Dramatic Shift in Perspective for Learners", The Internet and Higher Education, 2000, Vol. 2, No. 4, pp. 189-195

[9]. Birdsong, T. and Sharplin, W., "Peer evaluation enhances students' critical judgement", Highway One, 1986, Vol. 9, No. 1, pp. 23-28

[10]. Clifford, J., "Composing in stages: The effects of a collaborative pedagogy", Research in Teaching English, 1981, Vol. 15, No. 1, pp. $37-44$

[11]. Li, L.K.Y., "Some Refinements on Peer Assessment of Group Projects", Assessment and Evaluation Higher Education, 2001, Vol. 26, No. 1, pp. $5-18$

[12]. Cheng, W. and Warren, M., "Peer and Teacher Assessment of the Oral and Written Tasks of a Group Project", Assessment \& Evaluation in Higher Education, 1999, Vol. 24, No. 3, Sep. 1999, pp. $301-314$

[13]. Bridges, P., et al., "Discipline-related Marking Behaviour Using Percentages: a potential cause of inequity in assessment", Assessment \& Evaluation in Higher Education, 1999, Vol. 24, No. 3

[14]. Austin, M.J. and Brown, L.D., "Internet Plagiarism: Developing Strategies to Curb Student Academic Dishonesty", The Internet and Higher Education, 1999, Vol. 2, No. 1, pp. 21-33

[15]. Smith, P.J. and Smith, S.N., "Differences between Chinese and Australian students: some implications for distance educators", Distance Education, 1999, Vol. 20, No. 1

[16]. Scollon, R. and Scollon, S.W., Intercultural Communication. Language in society, ed. P. Trudgill, 1995, Oxford: Blackwell.

[17]. McLoughlin, C. and Oliver, R., "Designing learning environments for cultural inclusivity: A case study of indigenous online learning at tertiary level", Australian Journal of Educational Technology, 2000, Vol. 16, No. 1, Autumn 2000, pp. 58-72

[18]. Kraut, R., et al., "The HomeNet field trial of residential Internet services", Communications of the ACM, 1996, Vol. 39, No. 12, Dec 1996, pp. 55-63

[19]. Kraut, R., et al., "Internet Paradox: A social technology that reduces social involvement and psychological well-being?" American Psychologist, 1998, Vol. 53, No. 9, Sep 1998, pp. 1017-1031

[20]. Crook, C., Computers and the Collaborative Experience of Learning. International Library of Psychology, ed. P.K. Smith, 1994, London: Routledge.

October 10 - 13, 2001 Reno, NV 